\title{
http://dx.doi.org/10.35381/racji.v4i7.443
}

\section{Análisis de los tipos penales y su importancia para determinar responsabilidad penal}

\section{Analysis of criminal types and their importance in determining criminal responsibility}

Glenda Anabel Granda Torres

glendagranda30@gmail.com

Universidad Nacional de Loja, Loja

Ecuador

https://orcid.org/0000-0003-3173-726X

\author{
Carmen Del Cisne Herrera Abrahan \\ ccisneh@gmail.com \\ Universidad Técnica Particular de Loja, Loja \\ Ecuador \\ https://orcid.org/0000-0001-5909-2948
}

Recibido: 28 de abril de 2019

Aprobado: 25 de mayo de 2019

\section{RESUMEN}

Se realiza una revisión sobre los tipos penales y su importancia para determinar responsabilidad penal, se tiene que los tipos penales en el Ecuador se circunscriben según su estructura a delitos contra los derechos de la libertad, delitos contra el derecho del buen vivir, delitos contra el ambiente y la naturaleza o Pacha Mama, delitos contra la responsabilidad ciudadana, delitos contra la estructura del estado constitucional, delitos de terrorismo e infracciones de tránsito. La responsabilidad penal se determina en comprobación de la culpabilidad, nunca en presunción, lo cual se sustenta en el sistema finalista del delito vigente en el Ecuador.

Descriptores: Derecho penal; Criminología; Aplicación de la ley; Seguridad de Estado.

\section{ABSTRACT}

A review is carried out on criminal rates and their importance in determining criminal liability, criminal rates in Ecuador have to be limited according to their structure to crimes against the rights of freedom, crimes against the right to live well, crimes against 
environment and nature or Pacha Mama, crimes against citizen responsibility, crimes against the structure of the constitutional state, crimes of terrorism and traffic violations. Criminal responsibility is determined in proof of guilt, never in presumption, which is based on the finalist system of the crime in force in Ecuador.

Descriptors: Criminal law; Criminology; Law enforcement; State security.

\section{INTRODUCCIÓN}

Los tipos penales en el Ecuador se circunscriben según su estructura a delitos contra los derechos de la libertad, delitos contra el derecho del buen vivir, delitos contra el ambiente y la naturaleza o Pacha Mama, delitos contra la responsabilidad ciudadana, delitos contra la estructura del estado constitucional, delitos de terrorismo e infracciones de tránsito; en este sentido, la persona natural o jurídica que cometa un delito responderá a una sanción según lo tipificado en la responsabilidad penal, establecida para tal fin. Muñoz (2008) en su libro Teoría General del delito, donde destaca lo siguiente:

La norma jurídica penal pretende la regulación de conductas humanas y tiene por base la conducta humana que pretende regular. (...) De toda la gama de comportamientos humanos que se dan en la realidad, la norma selecciona una parte de comportamientos humanos que se dan en realidad, la norma selecciona una parte que se valora negativamente y conmina con una pena. Es pues, la conducta humana el punto de partida de toda reacción jurídico penal y el objeto al que se agregan determinados predicados (tipicidad, antijuricidad y culpabilidad) que convierten tal conducta humana en delito. Nuestro derecho penal es un derecho penal de ACTO y no de ACTOR.

Basado en el acto, el autor destaca que la persona posee cualidades que no pueden ser descritas a priori con eficacia en los tipos penales, pero sí establecer la responsabilidad penal producto del acto criminal cometido. Siendo necesario precisar lo jurídico concatenado a lo sociológico, por cuanto esto permite focalizar el accionar penal con mayor análisis por parte de los juristas con la finalidad de corresponder a la culpa adecuada al tipo penal violentado.

Por consiguiente en el Ecuador, se opercionaliza la justicia en función del sistema finalista de justicia, en este sentido, esta vertiente se comprende de los siguientes axiomas:

a) El delito deja de ser un fenómeno natural que es producido por una causa y 
acarrea una consecuencia o resultado, para convertirse en una realidad del ser social, ya que el derecho se edifica sobre la base de la naturaleza real de las cosas.

b) El concepto clásico del delito fue producto del pensamiento jurídico del positivismo científico, mientras que el finalismo partió de una fundamentación ético-social del Derecho Penal; y con ello, de una concepción ius filosófica, que retomó criterios aportados por el derecho natural , pues, como dice Welzel, "para el conocimiento de los valores recurrió a lo que precede a la existencia humana: el sujeto responsable, el carácter ordenado del actuar éticosocial y la concordancia de los órdenes ético-sociales".

c) Admite que el concepto del delito debe ser congruente con el fin y los medios del Derecho Penal y no con las causas y efectos (como un fenómeno natural). El fin estriba en la protección de la convivencia en comunidad frente a infracciones graves a la normatividad; mientras que el principal medio de que se sirve es la pena, traducida en la conminación e imposición de un mal estatal, en proporción a la gravedad de la lesión del Derecho, cuyo propósito es el mantenimiento de tal orden jurídico.

d) Representa el paso del subjetivismo al objetivismo. Como consecuencia el método que sigue el finalismo para estudiar la teoría general del delito se funda en un derecho penal de medios afines.

e) Reconoce que para fijar los criterios de punibilidad, la teoría del delito se debe fundar en la naturaleza de la acción perpetrada, y no en la personalidad del delincuente, en atención a que la imposición de la pena debe circunscribirse a una responsabilidad del acto y no responsabilidad de autor, que impide que al sujeto se le apliquen criterios de peligrosidad, temibilidad, reincidencia 0 habitualidad, como resabios de un positivismo que se encuentra en contradicción con los principios del Derecho natural. (Medina Peñaloza, 2005, pp. 136 y 137).

La culpa debe ser determinada por comprobación del delito y no por presunción del delincuente en sus antecedentes o características sociológicas que proyecten raciocinio sobre la culpabilidad, así se transciende de un enfoque lógico - deductivo 
a uno empírico - inductivo donde se hace necesario comprobar para determinar culpabilidad en el sujeto.

\section{Fundamentos de la responsabilidad penal}

En conformidad a las ideas de Cabello (2000), se dice que descansa la teoría de la responsabilidad humana, en la existencia de un yo capaz de mantener una conducta, un modo de existir distinto de los de los seres que lo rodean, a cuyo efecto resulta necesario poseer la capacidad de elegir, decidirse y ejecutar, constituyéndose por vía de aquellos actos en propietario de los mismos.

"Si como entes libres somos capaces de realizarnos de una u otra forma, de crear hechos y cosas, automáticamente nos convertimos en responsables de esas mismas cosas que hacemos, y de cargar a nuestra cuenta sus consecuencias, malas o buenas" (Cabello, 2000). Sin embargo, aún existe otro factor a considerar, concerniente a la permanencia de la identidad del yo. Pese a las variaciones temporales biológicas y ambientales, un denominador común en los proyectos de acción permite atribuir a cada persona, a través del tiempo, una filosofía psicológica particular.

La identidad consigo mismo (cualidad rectora del sentido de una vida) sufre, a raíz de las enfermedades mentales, un profundo quebranto a consecuencia del cual los actos emanados del yo alterado ya no le pertenecen, le son totalmente ajenos, extraños; por lo tanto, el paciente no responde por ello; en todo caso, la responsable sería la enfermedad. Análisis de la estructura dinámica de la responsabilidad:

1. Una manera didáctica de esclarecer y desarrollar el tema, es partiendo de la definición técnico-jurídica del delito, entendido éste como toda acción típicamente antijurídica y culpable. Ello implica el manejo de tres conceptos que, aunque concéntricos, por diferentes no deben confundirse: antijuridicidad, imputabilidad y culpabilidad. Desde otra sistemática, podremos ordenar estos elementos en dos presupuestos: 1) presupuesto objetivo: acto, tipicidad, antijuridicidad; 2) Presupuesto subjetivo: culpabilidad, la cual incluye la imputabilidad.

2. De acuerdo con Cabello (2000) "no es suficiente que un sujeto haya cometido 
un hecho típicamente antijurídico para que se lo declare responsable; además, es necesario que sea culpable, que medie una relación subjetiva entre el autor y el acto", relación que se establece mediante el ejercicio de las funciones psíquicas inherentes a una personalidad normal. Lo expuesto implica afirmar que el yo del autor se halla presente en el delito, que realmente es obra suya, y que en consecuencia se ha hecho acreedor a la retribución penal correspondiente. Mas para que esta circunstancia se verifique, resulta menester poseer los atributos psicológicos que personalicen el delito; en ello consiste la imputabilidad.

De lo anterior se colige pues, que desde el punto de vista jurídico, la pena posee un carácter retributivo; como tal, se presupone que quien ha de sufrirla es psicológicamente imputable, vale decir, capaz de comprensión y voluntariedad; única forma de poder retribuirle el accionar ilícito.

\section{Perspectiva sobre la responsabilidad penal}

\section{Concepto clásico y positivista}

Cuando se menciona el tema de la responsabilidad penal, parece surgir, indubitable, la referencia expresa a las razones por las cuales el delincuente debe soportar las consecuencias legales de su infracción. Las discrepancias existentes pueden resumirse en los postulados de la escuela clásica y la positiva:

Escuela clásica: libre albedrio.

Los postulados de esta escuela se basan en la autoría moral y el libre albedrío. Consideran los mismos que el hombre es un ser inteligente y libre, por lo que es capaz de comprender la naturaleza del acto que realiza y elegir entre el realizarlo o no. Puesto en la disyuntiva de optar entre el bien y el mal, al decidirse por esta última obra voluntariamente, cargando con sus consecuencias; de la misma manera en que se expone el autor de un libro por lo que ha escrito o un artesano por la obra realizada. (Cabello, 2000).

Asimismo, Grisanti (2014) destaca que para la Escuela Clásica, el fundamento de la imputabilidad es la responsabilidad moral. Así, para los defensores de esta posición, la imputabilidad y la responsabilidad penal se apoyan en la responsabilidad moral, la 
cual a su vez se asienta en la conciencia y libertad de los actos de una persona. Continuando con los alegatos de Grisanti (2014), se enfatiza la conceptualización de los elementos esénciales para esta escuela: Conciencia, entendida como la capacidad de entender la relevancia del acto que la persona se propone a realizar; y libertad, destinada a la decisión de la persona de poder escoger entre hacer o no tal acto.

No obstante, autores como Muñoz (2008) señalan que tal postura es insostenible no solo porque se basa en caso indemostrable como lo es la libertad de voluntad o libre arbitrio, sino también porque reduce todas las facultades humanas a los planos intelectivos y volitivos, que de acuerdo con este autor no son los únicos, y ni siquiera los más importantes. Sigue explicando que en todo caso, las facultades intelectivas y volitivas del ser humano, están condicionadas por otros factores que también pueden ser relevantes para determinar la capacidad de culpabilidad, como los sociales y culturales, razón por la cual no puede considerarse que la capacidad de culpabilidad sea únicamente problema de la conciencia y la libertad del actuar.

\section{Escuela positivista: determinismo}

Afirma Cabello (2000) que esta corriente postula la negación de la libertad moral del hombre y sostiene el determinismo cosmológico. Afirma que el ser humano no es más espontáneo en su conducta que la piedra que cae o la ameba que se retrae cuando se vierte una gota de ácido en el medio en que vive. Por lo tanto, asegura que el fundamento de la responsabilidad no ha de buscarse en el autor del delito, sino en la sociedad que tiene el derecho de defenderse. En opinión de Ferri, los actos del hombre pueden serle imputados, debiendo asumir la responsabilidad que le cabe en función de ellos, ya que el hombre se debe a una sociedad.

Tal como lo menciona Grisanti (2014), los seguidores de esta corriente le reprochan a los clásicos la ingenuidad de creer que existe el libre albedrío. Para ellos, el fundamento de la responsabilidad no puede ser moral, sino social: "el individuo es imputable por el hecho de vivir en sociedad" (Grisanti, 2014).

\section{Sobre el delito y sus elementos constitutivos:}

Afirma Cabello (2000) que una construcción dogmática de las más elaboradas la 
constituye la teoría jurídica del delito. Para explicarla, el referido autor toma los conceptos elementales de la vertiente más moderna, es decir, de la finalista. Para esta teoría, la acción, acto o conducta, el hacer voluntario del sujeto, es la base genérica sobre la cual se edifica la teoría, tomada de la realidad (concepto óntico-ontológico de acción). Continua explicando que "este fenómeno concreto que es la conducta humana, debe ser adjetivado para que podamos determinar qué conductas son delitos y cuáles no lo son", es decir, que de acuerdo con su criterio, el concepto de delito se presentará como algo estratificado, pero la estratificación será siempre el análisis, no el delito, que en todo momento sigue siendo una unidad.

No obstante, en cuanto lo que a esta investigación concierne, se ceñirá al aspecto jurídico del delito, entendido como "acto típicamente antijurídico, culpable es imputable a una persona, y castigado con una pena, o más ampliamente, una sanción penal" (Grisanti, 2014). Desde el punto de vista jurídico, el delito es toda conducta que el legislador sanciona con una pena, lo cual siguiendo el concepto aportado por Muñoz (2008), es una consecuencia del principio nullum crimen, nulla poena sine lege, que rige el moderno derecho penal.

Del concepto aportado por Grisanti (2014), se derivan los elementos o caracteres constitutivos del delito. No obstante, los mismos no serán examinados de manera profunda, solo serán enunciados en su aspecto positivo y negativo. De esta manera, se obtienen los siguientes elementos: acto, tipicidad, antijuricidad, imputabilidad, culpabilidad y punibilidad. Ahora bien, tal como lo afirma Grisanti (2014), a cada uno de esos elementos positivos del delito, le corresponden sus respectivos elementos negativos, los cuales excluyen la responsabilidad penal.

Así, se tiene que el aspecto negativo del acto, está constituido por las causas de ausencia de acción, el sueño artificial o hipnosis, los actos reflejo automático o inconsciente, el acto violentado, entre otros. En el caso de la tipicidad, su elemento negativo es la atipicidad, es decir, cuando el acto no está adecuado a ninguno de los tipos legales o penales consagrados en la ley penal. Respecto a la antijuricidad, su elemento negativo lo constituyen las causas de justificación, tales como la legítima defensa, el estado de necesidad, el ejercicio de un derecho subjetivo y el cumplimiento de un deber. 
Ahora bien, en el caso de la imputabilidad, su elemento negativo lo constituye la inimputabilidad, que tal como se explicará posteriormente, comprende la minoría de edad y la enfermedad mental suficiente para privar a la persona de la conciencia y libertad de sus actos. En cuanto a la culpabilidad, son el error de hecho esencial y el caso fortuito sus elementos negativos. Por último, respecto a la punibilidad, su elemento negativo lo constituyen las llamadas causas absolutorias.

Algunos autores dividen el delito en tales elementos y los separan caracterizándolos de acuerdo al aspecto objetivo y subjetivo del mismo, lo cual se conoce como noción analítica del delito, es decir, su tripartición y bipartición. No obstante, hay otra corriente de juristas que han opuesto a tal noción, señalando que de esta manera se fragmenta la unidad del delito o se selecciona el mismo en partes.

Arteaga (2006), señala que "evidentemente el delito es una unidad, pero ello, no impide la aplicación del procedimiento de análisis que debe utilizar también la ciencia del derecho penal para determinar lo que se requiere para que el delito surja como unidad" (p.116) y con base a la justificación de tal noción analítica, explica dos posiciones que se debaten en este tema, la concepción tripartita y la concepción bipartita.

De acuerdo con la primera concepción, es decir, la tripartita, la cual ha tenido una compleja evolución en la dogmática alemana a partir de la obra de Liszt y Beling, el concepto dogmático del derecho se estructura sobre la base de tres elementos 0 aspectos esenciales: la acción típica, la antijurídica y la culpabilidad, de la cual deriva la definición del delito como un acto típico antijurídico y culpable.

Por otro lado, la segunda concepción, o la bipartita, rechazan los postulados de la concepción anterior, por el hecho de considerar la antijuricidad como elemento del delito, pues sus partidarios consideran que la antijuricidad no puede ser considerada como un elemento más del delito junto con la acción y la culpabilidad.

En el delito no cabría distinguir sino dos elementos: uno objetivo (hecho material del hombre) y uno subjetivo (la voluntad). La antijuricidad entonces viene a ser la naturaleza intrínseca del delito, y como carácter esencial del delito, lo abarca en su totalidad. Es de mencionar que esta concepción es apoyada por Arteaga (2006) el cual sobre los lineamientos d esta última orientación explica en su libro, la antijuricidad 
como la esencia del delito o el delito en su unidad.

\section{Imputabilidad}

Muñoz (2008), señala que históricamente la imputabilidad aparece como una limitación de la responsabilidad penal de aquellas personas que tenían las facultades psíquicas mínimas para participar en la vida de la relación social como miembros de pleno derecho. Pronto se observó cómo los niños y enfermos mentales no podían ser tratados como adultos o los aparentemente sanos mentalmente. Así pues, la pena para ellos era algo inútil, y debía ser sustituida por otras medidas (reformatorios, manicomios) que en la práctica, tenían el mismo carácter de control social que la pena, pero que teóricamente no tenían el mismo sentido punitivo.

Ahora bien, para que pueda ser formulado el juicio de reproche o de culpabilidad del hecho cometido, el primer elemento requerido es la imputabilidad, no pudiéndose declarar culpable al incapaz o inimputable (Arteaga, 2006). Etimológicamente, el término "imputabilidad" significa atribuir, mejormente entendida como la posibilidad de atribuir a una persona determinada un acto por ella realizado (Grisanti, 2014). El autor anteriormente citado, ofrece una definición más precisa cuando se refiere a la imputabilidad de la siguiente forma:

Conjunto de condiciones físicas, psíquicas, de madurez y salud mental, legalmente necesarias para que puedan ser puestos en la cuenta de una persona determinada, los actos ticamente antijurídicos que tal persona ha realizado. Carlos Franco ha dicho que "es la capacidad de obrar en materia penal" (p. 175).

De acuerdo con Cabello (2000), la imputabilidad genéricamente considerada, "es el conjunto de condiciones que desde el punto de vista psicológico debe reunir una persona para que se le pueda atribuir la comisión de un delito a los fines que las leyes penales estatuyen". Asimismo, infiere el precitado autor que en un nivel menos técnico, se la puede definir como la "facultad de obrar normalmente, de observar una conducta que responda a las exigencias de la vida política de los hombre"; más sencillamente: la imputabilidad se basa en la salud mental.

Desde otra perspectiva, se puede decir que la imputabilidad es un concepto criminológico que se alcanza mediante la observación directa del individuo, tomando 
como referencia la ley penal. Tal afirmación coincide con la de Mezger, quien refiriéndose al art. 51 del Código Penal de Alemania, expresa que "...es la puerta por la que el derecho punitivo pasa al terreno de la moderna investigación de la personalidad" (citado por Cabello; 2000). En el caso del Ecuador, Silva Hernández (2014), señala que: "Según la posición de la Escuela Clásica, a la que se afilia el Código ecuatoriano en cuanto a la imputabilidad, los agentes se dividen en imputables e inimputables, según que haya o no obrado con conciencia y voluntad".

\section{Imputabilidad disminuida}

Después de haber desechado por impropia la denominación de semirresponsabilidad, los penalistas han convenido en llamarla imputabilidad disminuida. Cabello (2000) menciona que el concepto corresponde al pensamiento de Grasset: "Hay sujetos lo insuficientemente enfermos del psiquismo para no ser declarados normales y completamente responsables, pero que tampoco son suficientemente enfermos para ser declarados irresponsables, y a los que, por lo tanto, hay que declararlos semirresponsables" (p. 180).

Los psiquiatras de hoy han puesto de manifiesto la existencia de una zona intermedia entre la perfecta salud mental y la enajenación mental, en la cual no se está ni completamente alineado ni completamente sano. En relación a ello, Grisanti (2014) señala:

A este respecto, se sostiene, desde el punto de vista jurídico, que a una locura incompleta debe corresponder una responsabilidad incompleta, por tanto, la semilocura sería una causa de atenuación de la responsabilidad, y el semiloco será condenado a una pena menos grave que la que corresponde a un hombre normal (p. 178).

Respecto a la posible clasificación de alteraciones que entran dentro de esta cualidad de responsabilidad atenuada, Cabello (2000) explica:

He aquí la lista: neurosis, personalidades psicopáticas, alcoholismo crónico, debilidad mental, deterioros seniles y preseniles, defectos esquizofrénicos (esquizofrenias residuales), posconmociones de cráneo, posencefalitis, epilepsias (equivalentes), toxicomanías, encefalopatías, afasias, etc. El etcétera puede extenderse a cualquier sujeto que sin ser 
mentalmente enfermo tampoco sea enteramente sano. (p. 180)

De acuerdo con Arnaud (citado por Grisanti, 2014), los principales tipos de semialienaciones son a cleptomanía (tendencia irresistible al robo), la dipsomanía (estado patológico de los enfermos que se entregan con exceso y de modo irresistible al abuso de las bebidas), la piromanía (tendencia irresistible al fuego), entre otras. Así mismo, Chirino \& Giménez (2019), destacan que:

La justicia debe ser garante de elevar la dignidad humana para propiciar el buen vivir, esto implica compaginar acciones con los diversos organismos públicos y privados, en pro de fomentar una educación preventiva que permita contribuir en la disminución de la criminalidad, y cuando sea cometido un delito, la sociedad tenga conciencian de la importancia que se castigue con prontitud y en proporción a la magnitud del mismo, de lo que se trata es de fomentar una ciudadanía protagónica.

Por consiguiente no se trata de inculpar a priori, sino de tener un juicio digno con la finalidad de promover un trato adecuado a la persona en virtud de su dignidad, aunado al sistema finalista del Ecuador, Aldana Zavala \& Isea, (2018), destacan la necesidad de fomentar la deontología kantiana como expresión del comportamiento humano en virtud de articular el buen vivir.

\section{Relación de los delitos en función del COIP}

En función de los delitos contra los derechos de libertad, estos se encuentran tipificados en el Código Orgánico Integral Penal (COIP), como aquellos relacionados en contra de los derechos humanos, lesa humanidad, trata de personas, delitos contra la inviolabilidad de la vida, contra la integridad personal, de violencia contra la mujer o miembros del núcleo familiar, contra la libertad en estricto sentido, integridad sexual y reproductiva y delitos contra la igualdad.

En cuanto a los delitos contra el derecho del buen vivir y delitos contra el ambiente y la naturaleza o Pacha Mama, se encuentran los delitos que atentan a la salud, delitos contra la seguridad de los activos de los sistemas de información y comunicación, contra los derechos de consumidores y usuarios, derecho al trabajo, contra la biodiversidad y recursos naturales no renovables; entendiendo cuales son los elementos objetivos y subjetivos de cada uno de los tipos penales, las posibles formas 
de participación en autoría y complicidad, y el correspondiente estudio de la consumación y la tentativa punible.

En función de los delitos contra la responsabilidad ciudadana, delitos contra la estructura del estado constitucional, delitos de terrorismo e infracciones de tránsito, se encuentran los delitos contra la tutela judicial efectiva, la eficiencia en la administración pública, el régimen de desarrollo, la administración aduanera, el régimen monetario, delitos económicos, contra el sistema financiero, contra la fe pública, derechos de participación, delitos contra la estructura del estado constitucional, los cuales atentan contra su seguridad pública, el terrorismo y de las infracciones de tránsito. (Andrade Castillo, 2018).

\section{REFERENCIAS CONSULTADAS}

1. Andrade Castillo, X. (2018). Programa de enseñanza aprendizaje COIP. Recuperado de http://www.fiscalia.gob.ec/files/escuela\%20fiscales\%20docs/MODULO 1 COI P.pdf

2. Aldana Zavala, J., \& Isea, J. (2018). Derechos Humanos y Dignidad Humana. IUSTITIA SOCIALIS, 3(4), 8-23. Recuperado de http://fundacionkoinonia.com.ve/ojs/index.php/lustitia Socialis/article/view/119 $\underline{101}$

3. ARTEAGA Sánchez, A. (2007). Derecho penal venezolano, Caracas.

4. Cabello V. (2000) Psiquiatría forense en el derecho penal. (1er reimpresión, dos tomos) Hammurabi, José Luis Depalma Editor. Buenos Aires, Argentina.

5. Chirino, L., \& Giménez, M. (2019). Conducta criminal y su relación con la imputabilidad como elemento del delito. IUSTITIA SOCIALIS, 4(6), 28-51. doi:http://dx.doi.org/10.35381/racji.v4i6.287

6. Grisanti H. (2014). Derecho Penal. Parte General. Editorial Vadell Hermanos.Venezuela.

7. Medina Peñaloza, S, (2005) Teoría del delito, Angel Editor, México.

8. Muñoz. F, (2008) Teoría general del delito, $4^{\mathrm{a}}$ ed., Tirant lo blanch, Valencia, Venezuela.

9. Silva Hernández, G. (2014). Imputabilidad, fuero de menores y el tipo penal, 
recuperado de https://www.derechoecuador.com/codigo-organico-integralpenalimputabilidad-fuero-de-menores-y-el-tipo-penal-

\section{REFERENCES CONSULTED}

1. Andrade Castillo, X. (2018). COIP learning teaching program. Retrieved from http://www.fiscalia.gob.ec/files/escuela\%20fiscales\%20docs/MODULO $1 \mathrm{COI}$ P.pdf

2. Aldana Zavala, J., \& Isea, J. (2018). Human Rights and Human Dignity. IUSTITIA SOCIALIS, 3 (4), 8-23. Retrieved from http://fundacionkoinonia.com.ve/ojs/index.php/lustitia Socialis/article/view/119 $\underline{101}$

3. ARTEAGA Sánchez, A. (2007). Venezuelan criminal law, Caracas.

4. Cabello V. (2000) Forensic psychiatry in criminal law. (1st reprint, two volumes) Hammurabi, José Luis Depalma Editor. Buenos Aires, Argentina.

5. Chirino, L., \& Giménez, M. (2019). Criminal conduct and its relationship with imputability as an element of crime. IUSTITIA SOCIALIS, 4 (6), 28-51. doi: http: //dx.doi.org/10.35381/racji.v4i6.287

6. Grisanti H. (2014). Criminal law. General Part Editorial Vadell Brothers. Venezuela.

7. Medina Peñaloza, S, (2005) Crime theory, Angel Editor, Mexico.

8. Muñoz. F, (2008) General theory of crime, 4th ed., Tirant lo blanch, Valencia, Venezuela.

9. Silva Hernández, G. (2014). Imputability, jurisdiction of minors and the criminal type, recovered from https://www.derechoecuador.com/codigo-organicointegral-penalimputabilidad-fuero-de-menores-y-el-tipo-penal-

\footnotetext{
C2019 por los autores. Este artículo es de acceso abierto y distribuido según los términos y condiciones de la licencia Creative Commons Atribución-NoComercial-Compartirlgual 4.0 Internacional (CC BY-NC-SA 4.0) (https://creativecommons.org/licenses/by-nc-sa/4.0/).
} 